\title{
Propagação vegetativa por miniestacas de preciosa (Aniba canellila (H. B.K) MEZ)
}

\author{
Paulo de Tarso Barbosa SAMPAIO ${ }^{1}$, Jhansem Antonio Silva de SIQUEIRA²; Suely COSTA ${ }^{1}$; Flavio Mauro \\ Souza BRUNO ${ }^{1}$
}

\section{RESUMO}

Este trabalho teve como objetivo o enraizamento de miniestacas de material juvenil da preciosa (Aniba canelilla (H.B.K) $\mathrm{Mez}$ ), tratadas com diferentes concentraçóes de ácido indol-3-butirico (AIB) na forma líquida. As miniestacas foram obtidas de mudas de regeneração natural com aproximadamente um ano de idade e modeladas com $5 \mathrm{~cm}$ de comprimento e 0,4 - 0,6 $\mathrm{mm}$ de diâmetro. O experimento foi conduzido em casa de vegetaçấo, com sistema de nebulização intermitente regulada em 20 segundos para aspersóes com intervalos de 20 minutos. Como substrato foi utilizado areia lavada. Semanalmente foram feitas aplicaçôes de fertilizante foliar e fungicida. O experimento foi delineado em cinco blocos inteiramente ao acaso, com cinco tratamentos (0,300 ppm, 600 ppm, 1200 ppm e 2000 ppm de AIB) com 25 miniestacas/tratamento, totalizando 125 miniestacas no experimento. Após 180 dias do plantio, as miniestacas foram retiradas do substrato e avaliados os seguintes parâmetros: porcentagem de enraizamento, porcentagem de sobrevivência, porcentagem de calo; porcentagem de brotos; número de raízes principais, comprimento médio das raízes; peso da matéria seca dos brotos e peso da matéria seca das raízes. Os resultados indicam que a emissão de raízes das estacas de material juvenil da preciosa independe do uso do AIB. Entretanto, o uso desta auxina na concentração de 2000 ppm estimulou o enraizamento (79,04 \%); sobrevivência (89,43\%) e brotaçáo (64\%) das miniestacas.

PALAVRAS-CHAVE: preciosa, auxinas, material juvenil, miniestacas

\section{Vegetative propagation by mini-cuttings of preciosa (Aniba canelilla (H.B.K) Mez)}

\section{ABSTRACT}

This study aimed to the rooting of minicuttings of juvenile material of preciosa (Aniba canelilla (H.B.K) Mez), through the use of concentrations of 0,300 ppm, $600 \mathrm{ppm}, 1200 \mathrm{ppm}$ and $2000 \mathrm{ppm}$ of acid indole-3-butirico (IBA) in liquid form. The cuttings were obtained from seedlings of natural regeneration with approximately one years of age and shaped with $5 \mathrm{~cm}$ long and $0.4-0.6 \mathrm{~mm}$ in diameter. The experiment was conducted in a greenhouse, with intermittent mist system governed by 20 seconds to mist at intervals of 20 minutes. As substrate was used sand washed. Weekly applications were made from fertilizer and foliar fungicide. The design used was completely randomized with five treatments and twenty-five repetitions, totaling 125 minicuttings. After 180 days after planting, the minicuttings were taken from the substrate and evaluated the following parameters: percentage of rooting, percentage of survival, percentage of calluses, dry weight of the sprouts, number, size and dry weight of roots. The results indicate that the rooting of minicuttings of juvenile material of preciosa independent of the use of the IBA. However, the use of auxin in the concentration of $2000 \mathrm{ppm}$ stimulated rooting $(79.04 \%)$, survival $(89.43 \%)$ and sprouted $(64 \%)$ of minicuttings.

KEY WORDS: preciosa, auxin, juvenile material, minicutting

1 Instituto de Pesquisas da Amazônia (INPA), Coordenação de Pesquisa em Silvicultura Tropical (CPST), (092) 3643 1836, Caixa Postal 478, Manaus, AM, CEP 69060-001, E-mail: sampaio@inpa.gov.br

2 Eng ${ }^{0}$ Florestal, M.Sc. 


\section{INTRODUÇAO}

A preciosa (Aniba canelilla (H.B.K) Mez) é amplamente distribuída nas matas de terra firme da Guiana Francesa, Venezuela e Peru. No Brasil, ocorre nos estados do Pará e Amazonas. É uma espécie produtora de óleo aromático, com alto teor de nitrofeniletano, um odorífero natural com grande demanda por parte das industrias de perfumaria. Na regiấo Amazônica, a infusão da casca da preciosa tem sido utilizada para o tratamento de diarréia, peitoral, antiespasmódico e estimulante do sistema nervoso (Taveira et al., 2003).

O uso principal da preciosa é a extração do óleo a partir da madeira, galhos e folhas (Lima et al., 2004). Analise do conteúdo do óleo destilado de indivíduos adultos apresentou $71,2 \%$ de nitrofeniletano (folhas) e $68,2 \%$ nos galhos finos (Lima et al., 2004). Entretanto, o óleo comercializado no mercado é originado da madeira do fuste desta espécie, fato que causa o corte indiscriminado de árvores adultas em idade reprodutiva, limitando ainda mais a disponibilidade de sementes para a implantação de plantios "ex situ" e "in situ" (Sampaio, 2000).

O uso da propagaçáo vegetativa por miniestacas torna-se uma alternativa para propagação desta espécie, possibilitando a multiplicação de genótipos que alie produtividade e qualidade do óleo. Entretanto, a maioria das essências florestais diminui a capacidade da emissão de raízes com o aumento da idade da árvore (Hartmann et al., 2002). Este fato, foi constatado por Menezes (2006) que concluiu que estacas de material adulto de Aniba rosaeodora Ducke (pau-rosa), não desenvolviam raízes mesmo quando tratadas com concentraçóes de 0, 2000, 4000, 5000 e 6000 ppm de AIB em ambientes com luz e umidade controlados.

Algumas substâncias de ocorrência natural nas plantas e com propriedades semelhantes aos hormônios atuam na iniciação das raízes. Da mesma forma, várias classes de reguladores de crescimento como auxinas, citocininas, giberelinas, etileno e alguns inibidores como acido abscísico influem na iniciação de raízes (Fogaça e Fett-Neto, 2005; Hartmann et al., 2002). Atualmente, os hormônios são produzidos também sinteticamente e, com sua aplicação na induçáo de raízes (Hartmann et al., 2002). As principais auxinas sintéticas produzidas em laboratório são: ácido indolbutírico (AIB) e o ácido naftalenoacético (AIA), que podem ser encontrados comercialmente sob a forma líquida, pasta ou pó. A concentração, para aplicação nas estacas varia conforme o tipo de estacas e com a espécie (Fogaça e Fett-Neto, 2005).

As condiçóes internas da planta podem ser traduzidas pelo balanço hormonal entre inibidores e promotores de enraizamento. Quando ao balanço hormonal entre promotores e inibidores é favorável aos promotores, ocorre o processo de iniciação radicular (Marenco e Lopes, 2005; Veiga, 2004). Uma das formas mais comuns de favorecer o balanço hormonal, segundo Fogaça e Fett-Neto, 2005, é a aplicação exógena de reguladores de crescimento sintéticos, os quais elevam o teor de auxinas no tecido.

Outros fatores como idade do material de origem das estacas, juvenilidade dos brotos, a posiçáo do broto do qual as estacas são retiradas, diâmetro das estacas, a presença de gemas e/ou folhas, estado nutricional e os efeitos ambientais, como a umidade; luminosidade; substrato e fotoperíodo são preponderantes para a emissão de raízes (Corrêa e Fett-Neto, 2004 ). O viveiro de formação de raízes deverá ser dotado de sistemas de nebulização, permitindo elevada umidade, luminosidade mediana e temperaturas em torno dos $26^{\circ} \mathrm{C}$. Em lugares onde náo é possível esta infra-estrutura, deve-se optar por caixas propagadoras, que são estruturas totalmente fechadas, proporcionando alta a umidade do ar no interior das caixas (Hartmann et al., 2002). Este trabalho teve como objetivo avaliar o enraizamento de miniestacas com folhas de material juvenil de preciosa quando submetidas a 300, 600, 1200 e 2000 ppm de AIB.

\section{MATERIAL E MÉTODOS}

O experimento foi realizado no período de abril a outubro de 2004, no viveiro de enraizamento do INPA/V8, latitude de $02^{\circ} 08^{\prime} 07^{\prime}$ "S, longitude de $60^{\circ} 01^{\prime} 38^{\prime \prime} \mathrm{W}$. O clima tipo "Ami" com pluviosidade e temperatura media anual de $2.458 \mathrm{~mm}$ e $25,6^{\circ} \mathrm{C}$ respectivamente com estação seca de junho a outubro (Salati et al., 1998).

Foram coletadas miniestacas do ápice de mudas de regeneração natural com aproximadamente um ano de idade. $\mathrm{Na}$ casa de vegetaçấo, as miniestacas foram modeladas com comprimento médio de $5 \mathrm{~cm}$ e diâmetro entre $4 \mathrm{a} 6 \mathrm{~mm}$. A extremidade basal cortada em forma de bisel e com um par de folhas reduzidas pela metade para diminuir a transpiração. Após a modelagem, as miniestacas foram submersas por 15 minutos, em uma solução de fungicida sistêmico Benlate $500\left(3 \mathrm{~g} .^{1-1}\right)$ e posteriormente lavadas em água corrente para retirar o excesso de fungicida. A seguir, as bases das miniestacas foram imersas por 10 segundos, em uma solução alcóolica de AIB (50\%) nas dosagens de 0, 300, 600, 1200 e 2000 ppm. $\mathrm{O}$ experimento foi conduzido no viveiro de enraizamento, com sistema de nebulizaçáo intermitente com intervalos de 20 minutos. A proteçấo contra a incidência direta dos raios solares foi obtida através do uso de telas de proteçáo (75\%). Foi utilizado areia lavada como substrato e o período de observação do experimento no viveiro de enraizamento foi de 180 dias. Quinzenalmente foi aplicado sobre a superfície das folhas, adubo com a seguinte composição química: $\mathrm{N}$ total $-6 \% ; \mathrm{P}_{2} \mathrm{O}_{5}-6 \% ; \mathrm{K}_{2} \mathrm{O}-8 \% ; \mathrm{Mg}-0,5 \% ; \mathrm{S}-0,5 \%$; $\mathrm{B}-0,03 \% ; \mathrm{Zn}-0,05 \% ; \mathrm{Fe}-0,1 \%$; Mn - 0,03\%. Foram avaliadas as seguintes variáveis: porcentagem de enraizamento (\%), porcentagem de sobrevivência (\%), número de raízes, 
comprimento de raízes $(\mathrm{cm})$, porcentagem de calos (\%), porcentagem de brotos (\%), peso da massa seca dos brotos $(\mathrm{g})$, peso da massa seca das raízes $(\mathrm{g})$. Este experimento foi delineado em cinco blocos inteiramente ao acaso, com cinco tratamentos $(0,300,600,1200$ e $2000 \mathrm{ppm})$ e 25 miniestacas/ tratamento, totalizando 125 miniestacas. Os dados foram submetidos a analise de variância e a comparaçáo das medias pelo teste de Tukey a 5\% de probabilidade. Para efeito da analise estatística, os dados da porcentagem de enraizamento e sobrevivência, foram transformados pela relação arco seno $(\sqrt{x+0,5})$ e para percentagem de calos, os dados foram transformados em arco seno $(x+0,1)$. Foram realizadas analises de correlação através dos Programas SAEGE e SAS.

\section{RESULTADOS E DISCUSSÕES}

As maiores porcentagens de enraizamento, número de raízes/mini-estaca e comprimento de raízes foram observadas nas estacas tratadas com o AIB nas concentraçóes de 300, 600, 1200 e 2000 ppm, indicando que o uso do AIB estimulou o sistema radicular das miniestacas de material juvenil desta espécie. Entretanto, 38,8\% das miniestacas que não foram submetidas as diferentes dosagens de AIB, desenvolveram sistema radicular (testemunhas), indicando a emissão de raízes das miniestacas de material juvenil desta espécie, independe do uso do AIB (Tabela 1).

É grande o numero de estudos que compravam a eficiência das auxinas sintéticas no enraizamento de estacas de espécies lenhosas. Menezes (2006) comprovou a eficiência do AIB para estimular o enraizamento de estacas de material juvenil de pau-rosa (Aniba rosaeodora Ducke). Neves et al. (2006); Noberto et al. (2001); concluíram que concentraçôes que variavam entre 300 a 4000 ppm de AIB contribuíram para o enraizamento de estacas de espécies lenhosas.

Neste estudo, as miniestacas tratadas com AIB, desenvolveram raízes maiores e em maior numero que as estacas testemunhas (Tabela 1). Espécies como a preciosa cujas sementes são intensamente pedradas por pássaros e brocas de insetos, a produção de mudas a partir de miniestacas pode se constituir como uma importante alternativa de reprodução. Mudas vigorosas, com sistema radicular mais desenvolvido, tem maior probabilidade de sobreviver e crescer mais rápido em condiçóes adversas de campo.

A elevada sobrevivência das miniestacas $(81,65 \%)$ após 180 dias da instalação do experimento no viveiro de enraizamento (Tabela 2), demonstra que fatores ambientais como umidade e temperatura dentro do viveiro de enraizamento, foram adequadamente controlados pelo uso do sistema de nebulizaçáo.

Estudos indicam que a elevada umidade relativa do ar dentro do viveiro, contribui para permanência das folhas nas estacas (Hartmann et al., 2002). Fato este, observado neste experimento. A constante nebulização dentro do viveiro, reduziu a transpiração das folhas e a morte por desidratação das miniestacas. Outros fatores como a adubaçấo foliar e o controle de fungos através da aplicação quinzenal de fungicida, certamente contribuíram para elevar a sobrevivência das miniestacas durante o período experimental. Azevedo (1999) e Gondim et al. (2001) encontraram resultados semelhantes ao avaliarem a sobrevivência de estacas de cupuaçuzeiro (Theobroma grandiflorum).

Em muitas espécies florestais, a formaçáo de calo pode ser precursor da formação de raízes nas estacas (Hartmann $e t$ al., 2002). Nesta espécie, a emissão de raízes, independe da formação de calo. Observa-se que a formação de raízes nas miniestacas de preciosa não é diretamente proporcional á formaçáo de calos (Tabela 1). Entretanto, as miniestacas que apresentaram maior formaçáo de calos não foram tratadas com AIB (testemunhas), revelando que o uso desta auxina estimulou a formação de raízes (Tabela 1).

Após 180 dias da implantação do experimento, o sistema radicular já estava desenvolvido e grande número das miniestacas apresentava brotaçôes. Observa-se que existe correlaçáo positiva entre a formaçáo do sistema radicular e o número de folhas totais (folhas remanescentes + brotaçôes) (Figura 1). Nota-se que a emissão de brotos nas miniestacas de preciosa é diretamente proporcional á formação de raízes,

Tabela 01 - Comparação das médias pelo teste de Tukey (5\%) para porcentagem de enraizamento (\%), comprimento de raízes (cm), número de raízes principais e porcentagem de calos (\%) em miniestacas de material juvenil de Preciosa (Aniba canellila) aos 180 dias INPA. Manaus - AM.

\begin{tabular}{lcccc}
\hline Concentração (AIB - ppm) & $\begin{array}{c}\text { Enraízamento } \\
(\%)^{\mathrm{a}}\end{array}$ & $\begin{array}{c}\text { Comprimento de raízes } \\
(\mathrm{cm})\end{array}$ & $\begin{array}{c}\text { Número de raízes principais } \\
\text { Calos }(\%)^{\mathrm{b}}\end{array}$ \\
\hline 0 & $38,81 \mathrm{~b}$ & $4,41 \mathrm{a}$ & $0,88 \mathrm{a}$ & $33,75 \mathrm{a}$ \\
300 & $63,59 \mathrm{ab}$ & $7,87 \mathrm{ab}$ & $1,80 \mathrm{ab}$ & $13,94 \mathrm{ab}$ \\
600 & $79,04 \mathrm{a}$ & $8,09 \mathrm{ab}$ & $1,96 \mathrm{ab}$ & $11,28 \mathrm{ab}$ \\
1200 & $74,20 \mathrm{a}$ & $8,39 \mathrm{ab}$ & $1,72 \mathrm{ab}$ & $11,41 \mathrm{ab}$ \\
2000 & $79,04 \mathrm{a}$ & $9,02 \mathrm{~b}$ & $2,28 \mathrm{~b}$ & $6,340 \mathrm{ab}$ \\
Média & 66,94 & & & 15,34 \\
C.V. $(\%)$ & 27,55 & 28,83 & 34,37 & 17,22 \\
\hline
\end{tabular}

${ }^{a}$ Dados transformados $(\sqrt{x+0,5})$; 'Dados transformados $(x+0,1)$. Médias seguidas da mesma letra não diferem entre si pelo teste de Tukey a $5 \%$ de probabilidade. 
indicando que o uso do AIB contribuiu positivamente para a formaçáo de raízes e brotos (Tabelas 1 e 2). Resultados similares foram observados por Azevedo (1999); Silva (2001); Veiga (2004) observaram que estacas de camu-camu (Myrciaria dubia (H.B.K.) Mc Vaugh), tratadas com maiores concentraçóes de AIB emitiram maior número de raízes e brotações.

Durante o período experimental, foi observado que miniestacas de preciosa que perderam as folhas não enraizaram e morreram por desidrataçáo. Este fato, já tinha sido observado por Menezes (2006) que concluiu que estacas de outra espécie de laurácea (pau-rosa) que perderam as folhas não enraizaram. Diversos estudos indicam que a presença de folhas nas estacas aumenta a síntese de carboidratos, contribuindo para o desenvolvimento de um sistema radicular mais vigoroso (Hartmann et al., 2002).

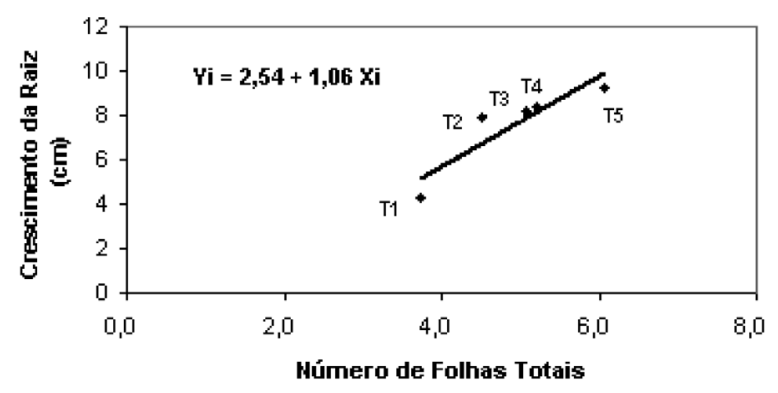

Figura 1 - Correlação entre a quantidade de folhas totais e 0 crescimento médio das raízes em miniestacas de preciosa (Aniba canelilla) aos 180 dias. INPA. Manaus/AM.

Nota-se que a massa verde e seca das folhas e raízes das miniestacas tratadas com diferentes concentraçôes de AIB é superior aos valores observados nas estacas testemunhas, fato que evidencia que o uso desta auxina, contribuiu de maneira favorável para formaçáo de novos brotos e crescimento das raízes (Tabela 1). Norberto et al. (2001), concluíram que o uso do AIB em estacas de figueira (Ficus carica L.) estimulou o crescimento da parte aérea e do sistema radicular. Manfroi et al. (1997), observaram que o uso do AIB aumentou o peso da matéria seca das raízes e dos brotos das estacas enraizadas de Quivi (Actinidia deliciosa (A. Chev.) C. F. Liang \& A.R. Ferguson). Outros estudos indicam que o uso de auxinas sintéticas a exemplo ao AIB, AIA e ANA estimulam o enraizamento e aumentam o peso da matéria seca das raízes das estacas de varias espécies da Amazônia central (Silva, 2001).

Os resultados observados neste estudo sobre enraizamento, sobrevivência, brotações, massa seca dos brotos e raízes das miniestacas de preciosa, complementam-se e indicam que a propagação vegetativa por estaquia desta espécie é possível sem o uso de auxinas. Entretanto, o uso do AIB aumentou de maneira significativa o enraizamento das estacas desta espécie.

Tabela 2 - Comparação das médias pelo teste de Tukey (5\%) da porcentagem de sobrevivência (\%), porcentagem de brotos (\%), peso da massa seca dos brotos ( $\mathrm{g}$ ) e peso da massa seca das raízes ( $\mathrm{g}$ ) das miniestacas de material juvenil de Preciosa (Aniba canellila) aos 180 dias- INPA. Manaus, AM.

\begin{tabular}{|c|c|c|c|c|}
\hline Tratamentos & Sobrevivência & Brotos & Peso da massa & Peso da massa \\
\hline AIB (ppm) & $(\%)^{\mathrm{a}}$ & $(\%)$ & $\begin{array}{l}\text { seca dos brotos } \\
\text { (g) }\end{array}$ & $\begin{array}{c}\text { seca das raízes } \\
\text { (g) }\end{array}$ \\
\hline 0 & $73,85 \mathrm{a}$ & $28 \mathrm{a}$ & $0,39 a$ & $0,08 \mathrm{a}$ \\
\hline 300 & $79,04 \mathrm{a}$ & $56 a b$ & $0,42 \mathrm{a}$ & $0,14 \mathrm{~b}$ \\
\hline 600 & $84,23 a$ & $56 a b$ & $0,44 \mathrm{a}$ & $0,17 \mathrm{~b}$ \\
\hline 1200 & $81,70 \mathrm{a}$ & $60 a b$ & $0,49 a$ & $0,14 \mathrm{~b}$ \\
\hline 2000 & $89,43 a$ & $64 \mathrm{~b}$ & $0,47 \mathrm{a}$ & $0,18 b$ \\
\hline Média & 81,65 & & & \\
\hline C.V. (\%) & 15,85 & 22,69 & 28,86 & 42,35 \\
\hline
\end{tabular}

a Dados transformados $(\sqrt{x+0,5})$. Médias seguidas da mesma letra não diferem entre si pelo teste de Tukey a $5 \%$ de probabilidade.

\section{CONCLUSÕES}

Os resultados obtidos neste estudo, permitem as seguintes conclusôes:

É possível a propagação vegetativa da preciosa pelo método da estaquia, independente do uso de auxinas sintéticas;

2. A aplicação do AIB nas dosagens de 300, 600, 1200 e 2000 ppm na forma líquida na base das estacas de preciosa, estimulou a formação de sistemas radiculares mais vigorosos;

\section{BIBLIOGRAFIA CITADA}

Azevedo, D. M. 1999. Effect of butyric acid (IBA) and substrate on the rooting of camu-camu (Myrciaria dubia (HBK) McVaugh). Monografia de conclusão de curso de graduação, Faculdade de Ciências Agrárias/Universidade Federal do Amazonas. Manaus, Amazonas. 40pp. (in Portuguese).

Sampaio, P.T.B. 2000. Preciosa (Aniba canellila), p.299-301. In: Clay, J. W.; Sampaio, P. T. B.; Clement, C.R. Amazonian Biodiversity: Examples and Strategies of Use. Instituto Nacional de Pesquisas da Amazônia, Manaus, Amazonas (in Portuguese).

Corrêa, L. R.; Fett-Neto, A. G. 2004. Effects of temperature on adventicious root development in microcutting of Eucalyptus saligna Smith and Eucalyptus globules Labil. Journal of Thermal Biology, 29, p.315-324.

Fogaça, C. M.; Fett-Neto, A. G. 2005. Role of auxin and its modulators in the adventitious rooting of Eucalyptus species differing in recalcitrance. Plant Growth Regulation. Vol. 45. p.1-10.

Gondim, T. M. S.; Ledo, F. J. S.; Cavalcante, M. J. B.; Souza, A. G. C. 2001. Effect of portion and length cutting at vegetative propagating of plants cupuaçu. Revista Brasileira de Fruticultura, 23(01): 203-205.

Hartman, H. T.; Kester, D. E.; Davies JR, F. T. D.; Geneve, R. L. 2002. Plant propagation: principles and practices. Prentice- 
Hall/Englewood Cliffs, New Jersey. $7^{\text {th }}$ ed. Upper saddle River: Prentice Hall.

Lima, M. da P.; Silva, T. M.D.; Silva, J.D.; Zoghbi, M.G.B.; Andrade, E. H. A. 2004. Essential oil composition of leaf and fine stem of Aniba canelilla (Kunth) Mez from Manaus, Brazil. Acta Amazonica,34(2): 329-330.

Manfroi, V.; Franciscone, A.H.D.; Barradas, C. I. N.; Seibert, E. 1997. Effect of IBA on rooting and development of cuttings of Kiwifruit (Actinidia deliciosa). Ciência Natural, 27(01): 43-45 (in Portuguese, with abstract in English).

Marenco, R. A.; Lopes, N. F. 2005. Plant Physiology: photosynthesis, respiration, water relations and mineral nutrition. Viçosa:UFV, $451 \mathrm{pp}$ (in Portuguese).

Menezes, A. 2006. Vegetative propagation of three amazon species: Rosewood (Aniba rosaeodora Ducke), Copaíba (Copaifera mulitijuga Hayne) and Breu (Protium apiculatum Swartz). Dissertação de mestrado. Instituto Nacional de Pesquisas da Amazonas/Fundação Universidade do Amazonas, Manaus, Amazonas. 83pp (in Portuguese).

Neves, T. S.; Carpanezzi, A. A.; Suffellato-Ribas, K. C.; Marenco, R. 2006. Rooting of the cork-saw depending on the type of cuttings and seasonal variations. Pesquisa Agropecuária brasileira, 41(12): 1699-1705 (in Portuguese, with abstract in English).
Norberto, P. M.; Chalfun, N. N. J.; Pasqual, M.; Veiga, R. D.; Pereira, G. E.; Mota, J. H. 2001. Effect of season of cutting and IBA in rooting of cutting Figueira (Ficus carica L.). Ciências Agrotecnicas. 25(3): 533-541 (in Portuguese, with abstract in English).

Salati, E.; Santos, A.A.; Lovejoy, T. E.; Klabin, I. 1998. Cimate changes. In: Why save the amazon Forest. INPA, Manaus, Amazonas. 114pp (in Portuguese).

Silva, M. L. 2001. Evaluation of seedling production of camucamu (Myrciaria dubia (H.B.K.) McVaugh) through cuttings of different diameters subjected to concentrations Fo naphthalene acetic acid - ANA. Dissertação de mestrado. Instituto Nacional de Pesquisas da Amazonas/Fundação Universidade do Amazonas, Manaus, Amazonas. 60pp (in Portuguese).

Taveira, F.S.M.; Lima, W.N.; Andrade, E.H.A.; Maia, J.G.S. 2003. Seasonal essencial oil variation of Aniba canelilla. Biochemical systematics and ecology. 31(1): 69-75.

Veiga, J. B. 2004. Effect of butyric acid on rooting of camu-camu cuttings (Myrciaria dubia (H.B.K.) McVaugh). Dissertação de mestrado. Instituto Nacional de Pesquisas da Amazonas/ Fundação Universidade do Amazonas, Manaus, Amazonas. 44pp (in Portuguese).

Recebido em 22/05/2009

Aceito em 14/01/2010 
